Robinson, Matthew B. (2000). From research to policy: Preventing residential burglary through a systems approach, American Journal of Criminal Justice 24(2): 169-179. Springer (ISSN: 1066-2316) DOI: $10.1007 / B F 02887590$ The original publication is available at www.springerlink.com

\title{
FROM RESEARCH TO POLICY: \\ Preventing Residential Burglary Through A Systems Approach
}

Matthew B. Robinson

\begin{abstract}
This paper isolates crime prevention policy implications which stem from a series of interrelated environmental studies of residential burglaries. A number of crime prevention strategies are developed using a systems approach. It is argued that changes made to the environments of individuals, groups, communities, organizations, and society can achieve lower risks of residential burglary victimization.
\end{abstract}

\section{INTRODUCTION}

All human behavior, including criminal activity, stems from interactions between numerous variables. Some of these variables occur at the micro-level of analysis, while others take place at the meso- and macro-levels (Goldstein, 1994; Jeffery, 1990). Given this orientation, effective crime prevention programs need to address multiple levels of variables simultaneously. All too often, crime prevention research does not get translated into realistic crime prevention strategies or policy. This paper represents an effort to counter this trend. It derives crime prevention policy implications from a series of environmental studies concerning residential burglary patterns. Burglary prevention strategies are discussed at different levels of analysis, including the individual, group, community, organization, and societal levels. The paper begins with a discussion of findings from four residential burglary studies and then moves to burglary prevention implications. 


\section{THE RESIDENTIAL BURGLARY STUDIES}

A series of environmental studies involving residential burglary patterns was launched in 1994. These studies were conducted exclusively at private apartment complexes surrounding a large state university in a capital city in the southeast United States. The first two studies (Robinson, 1997, 1998a) consisted of identifying and describing environmental conditions associated with student apartment residences that had reported at least one burglary to the police. Burglarized residences were compared with non-burglarized residences in terms of surveillability and accessibility to determine why some student apartment units experienced burglaries and others did not. The third and fourth studies (Robinson, 1998b, 1999) examined the role of victim occupancy patterns, lifestyles, and routine activities. Self-reported daily schedules were compared with estimated times of burglary incidents. In addition, activity patterns of street segments with high and low burglary levels were compared in terms of frequency and regularity of automotive and pedestrian traffic. Each of these studies is discussed in greater detail.

\section{Study 1: Surveillability and Residential Burglary}

The first study (Robinson, 1997) examines the relationship between surveillability and residential burglary at private apartment complexes in Tallahassee, Florida. Surveillability is "the extent to which a residence is overseen and observable by neighbors or passers by" (Cromwell, Olson, \& Avery, 1991, p. 35). Residences which are more surveillable or visible are at less risk for burglary. Most property offenders report being non-confrontational and wanting to avoid detection at all costs (Bennett \& Wright, 1984; Brown \& Altman, 1981; Cromwell et al., 1991; Maguire \& Bennett, 1982; Winchester \& Jackson, 1982; Wright \& Decker, 1994).

This study compared the surveillability of burglarized student apartments with non-burglarized units. Surveillability indicators included visibility of fronts, backs, sides, and entry points from other residences, from streets, from parking areas, and from other common areas, such as swimming pools and laundry facilities. The findings of the study were clear and also consistent with the existing literature. The entry points of burglarized dwelling units were less surveillable to neighbors and passers by than were non-burglarized residences. In other words, apartments with doors and windows obstructed by foliage and other objects exhibited higher victimization rates than units which were seen more easily from other residences, streets, parking lots, and common areas. This study suggests that increased levels of surveillability would contribute to lower levels of burglary.

\section{Study 2: Accessibility and Residential Burglary}

The second study (Robinson, 1998a) looks at the relationship between accessibility of student apartment units and residential burglary at private apartment complexes in Tallahassee, Florida. Accessibility refers to "indications of how easily the residence can be entered and how well the site is protected" (Cromwell et al., 1991, p. 35). Apartments which are more accessible to potential offenders are at greater risk of residential burglary victimization. These living spaces 
are easier to enter and exit without expending much time or energy (Bennett \& Wright, 1984; Brown \& Altman, 1981; Cromwell et al., 1991; Maguire \& Bennett, 1982; Wright \& Logie, 1988).

This study compared burglarized and non-burglarized student apartment units in terms of floor of residence, location of residence in building or on street, number and types of doors, number and types of locks, presence of special security precautions like bars or screens on windows, presence of alarms, window height from the ground, distance from residence to parking and of parking to street, and presence of a perimeter wall or fence. The findings were ambiguous and not consistent with previous literature. Student apartment units which had experienced burglaries were no more accessible to potential offenders than non-burglarized units. That is, there were virtually no statistically significant differences between burglarized and nonburglarized student apartment residences. The only meaningful differences were that burglarized residences were more likely to be located in the corner of a building or street and on the first floor of multi-level apartment complexes, thereby offering greater accessibility to potential offenders. These findings reiterate the well-established link between low levels of surveillability and burglary. In other words, these sites tend to be less observable than residences located on other parts of streets and buildings.

Curiously, even the most accessible student apartment units appeared to be at little risk for burglary victimization. In fact, the overall burglary rate for student apartments was substantially lower than for all other types of residences in the same area. After ruling out numerous explanations (such as a lower reporting rate and less attractive targets), the question of what accounted for the very low burglary rates remained. That observation spurred the next two studies.

\section{Study 3: Non-Occupancy and Residential Burglary}

The third study (Robinson, 1998b) investigates the relationship between non-occupancy and residential burglary. Non-occupancy refers to "any cues that someone is (not) home" (Cromwell et al., 1991, p. 37). Unoccupied residences are more susceptible to being burglarized. As mentioned earlier, most property offenders wish to avoid a confrontation with an occupant (Cromwell et al., 1991; Maguire \& Bennett, 1982; Rengert \& Wasilchick, 1985; Wright \& Decker, 1994).

This study compared self-reported daily schedules of student and non-student respondents with estimated times of burglary incidents. Self-reported daily schedules correlated highly with estimated times of burglary offenses. That is, the majority of burglaries took place at times when respondents indicated they were at work, school, shopping, or doing other things away from their domiciles. Burglary victimization was also highly associated with mean number of hours spent away from the residence. That is, residents who indicated they spent the least amount of time absent from their homes were least likely to have been burglary victims. This finding suggests that decreased periods of non-occupancy would result in lower burglary rates. 


\section{Study 4: Lifestyles, Routine Activities, and Residential Burglary}

The fourth study (Robinson, 1999) focuses on the role that lifestyles and routine activities play in burglary victimization. Lifestyles are "the activities that people engage in on a daily basis" and include "obligatory activities (e.g., going to work and school) and discretionary activities (e.g., engaging in recreation)" (Robinson, 1999, p. 39). Routine activities are "any recurrent and prevalent activities which provide for basic population and individual needs . . . including formalized work, leisure, social interaction, learning.., which occur at home, in jobs away from home, and in other activities away from home" (Cohen \& Felson, 1979, p. 593).

This fourth study combined random telephone surveys of area residents with on-site observations of movement patterns on randomly selected residential streets. This strategy allowed direct measurement of lifestyles and routine activities rather than simply relying upon self-reports. Respondents were compared in terms of their lifestyles and routine activities. Selfreported daily schedules (hours spent at work and school, trips to sporting events, bars, clubs, movies, restaurants, shops, and walking or driving) were obtained. Additionally, observed activity patterns of street segments (i.e., frequency and regularity of automotive and pedestrian traffic)-which are created, in part, by lifestyle differentials of residents-were assessed against burglary rates.

Self-reported daily schedules correlated highly with burglary rates. Respondents who spent less time away from home were less likely to become burglary victims. Similarly, participants with irregular schedules were less likely to become burglary victims. Burglary was also more prevalent on street segments with lower levels and irregular patterns of automotive and pedestrian traffic. That is, burglaries occurred at greater rates where there was less potential for surveillability and where resident non-occupancy patterns were more predictable. All in all, this study suggests that increased levels of surveillability resulting from higher levels of movement patterns and from decreased regularity of movement patterns would lead to lower burglary rates.

\section{SUMMARY}

The third and fourth studies account for the curious finding in the second study. There it was learned that even though many residences were highly accessible to potential offenders and obstructed from the view of neighbors and passers by, they were not burglarized. The last two studies suggest that a major impediment to burglary is the resident's lifestyle and the routine street activities which stem from the lifestyles of potential victims, their neighbors, and passers by. In other words, otherwise suitable and attractive burglary targets were avoided when surrounding activity patterns were high and unpredictable, thereby increasing potential for surveillability and detecting potential offenders in the area. The policy implications one can derive from these studies are addressed in the next section of this paper. 


\section{IMPLICATIONS FOR BURGLARY PREVENTION}

The findings from this series of studies can help develop appropriate burglary prevention strategies. As mentioned earlier, a systems perspective provides a unique way of looking at human behavior. This viewpoint assumes that organisms and environments are continuous, mutual influences upon each other. It also subsumes various levels of analysis, including the individual or micro-level, the meso-level (group, community, organization), and societal or macro-level (Jeffery, 1990; Miller, 1978; Whitehead, 1925). As Jeffery (1990, p. 25) explains, systems theory "is rooted in the interrelationship of parts with the whole and with the flow of energy and information from one subsystem to another subsystem."

The studies discussed in this paper locate numerous factors related to residential burglary victimization. They include surveillability, accessibility, non-occupancy patterns, lifestyles, and

routine activities in the surrounding environment. Since behavior, including residential burglary, results from multiple interactions, the most effective crime prevention strategies will integrate as many levels of analysis as possible. The policy implications in this paper are organized around five interacting levels of analysis. They consist of the individual, group, community, organization, and societal levels. The effectiveness of a policy change aimed at one level of analysis may depend upon supplementary changes made at other levels. As a result, burglary prevention policies which promote changes at one level of analysis should be made only after anticipating possible repercussions at other levels of analysis.

\section{INDIVIDUAL-LEVEL STRATEGIES}

The most obvious burglary prevention policy implications in a systems analysis start at the individual level. According to Cohen and Felson (1979, p. 605), "the opportunity for predatory crime appears to be enmeshed in the opportunity structure for legitimate activities to such an extent" that it might "be very difficult to root out substantial amounts of crime without modifying much of our way of life." To reduce risks for residential burglary, individual residents who live alone should vary their daily work and leisure schedules as much as possible. Logically, this would create higher levels of irregular routine activities around their residences and make their non-occupancy patterns less predictable to potential offenders, thereby lowering the chances for residential burglary. Individuals who live with other people should coordinate their schedules with roommates, spouses, and children so there is less overlap between their daily schedules. Although this strategy may interfere with meaningful personal interactions, routine activities that are higher in volume and less predictable should reduce the household's risk for burglary victimization.

These suggestions clearly depend on factors which may go beyond the scope of an individual level of analysis. For example, people who wish to change their daily discretionary activities must seek and gain support of those who dictate, control, or structure their daily obligatory activities. Additionally, people with roommates, spouses, and children who coordinate their schedules to create even the illusion of higher volumes of routine activities around their residences must seek and gain the support and cooperation from the others involved. 
Therefore, even individual-level policies derived from this research depend upon and affect factors from other levels of analysis. According to Garofalo (1987, p. 40), lifestyles are shaped by social forces that include role expectations and structural constraints. Since both role expectations and structural constraints (and therefore, lifestyles) are influenced by public policies, "implications for the risk of victimization should be taken into account as costs and benefits when (crime control) policies are considered" (Garofalo 1987, p. 41). For example, movement patterns of people should be taken into account and altered so that offenders and targets seldom converge in the absence of handlers and guardians (Felson, 1987, p. 928).

This observation means that larger scale changes in how people move through residential environments should be planned with crime prevention in mind. Felson (1987, p. 912) suggests "the flows of routine activities could be diverted ever so slightly to reduce crime, without sacrificing prosperity or freedom" (see an actual example described in Felson 1987, p. 929). Apartment designers, then, could divert flows of likely offenders away from potential targets (Felson 1987, p. 927).

The daily movements of potential victims should be guided and channeled in ways which reduce exposure to risk. The findings of these studies suggest that lifestyles and routine activities are related to residential burglary victimization. The degree to which individuals can alter their lifestyles so as to promote higher volumes of irregular pedestrian and automotive traffic should affect their risks of residential burglary victimization.

Whether individuals can choose to engage in more or less obligatory and discretionary activities or whether they are constrained by economic, political, and social forces beyond their control is an interesting matter of debate (e.g., see Roundtree \& Land 1996, pp. 151-152). Most people are not in a position to engage in unlimited amounts of discretionary activities because of constraints that obligatory activities place upon them. In these instances, residents should strive to create the illusion they are home and/or increase the total period of actual occupancy. For instance, individuals should live as close to work as possible to facilitate coming home for lunch to serve as a guardian of the property.

\section{GROUP-LEVEL STRATEGIES}

At the group level, people who are seeking roommates should look for others who have different daily schedules. Groups of people already living together in a residence should coordinate their schedules so as to enhance levels of guardianship. When lifestyles of roommates are varied, people are coming and going at all different hours of day and night. These habits increase the volume of routine activities at and around the residence, and also decrease the regularity or predictability of non-occupancy. Sometimes it is difficult or impossible to vary lifestyles in order to reduce crime victimization risks. In these situations, it may be that groups of people can watch each other's residences and serve as guardians to defend against would-be burglars. 


\section{COMMUNITY-LEVEL STRATEGIES}

At the community level, neighbors should get to know each other, form strong bonds, and look out for each other's property. When neighbors are guarding each other's property, crime should decrease in that area. However, increased social solidarity probably will make very little difference unless burglars know about the cohesion among neighbors. Therefore, neighbors should not only interact and socialize, but they should also be visible doing so. Since many burglars watch and track the actions of their potential victims (Wright \& Decker, 1994), it is likely that they pay more attention to what people do rather than to signs announcing the presence of a neighborhood watch program. Additionally, neighbors can collect mail and newspapers when residents are out of town, thereby decreasing the likelihood that burglars will recognize signs of non-occupancy. This practice can benefit the entire community as well. When burglars see cues which suggest one suitable target, they are likely to scour the neighborhood for signs of other attractive targets. The mere presence of an opportunistic burglar in the neighborhood increases risks for other residences. Communities should take appropriate steps to eliminate the presence of all suitable targets.

Increasing solidarity whereby "residents pool their resources to increase guardianship of their own property and that of their neighbors" (Cohen \& Cantor, 1981, p. 125) to decrease property crime rates may not be necessary in some cases. The line of research presented in this paper suggests that areas with high levels of irregular routine activities, even under conditions of poor informal social control, can have lower residential burglary rates. The study indicates students are less likely than non-students to know their neighbors. Yet, the risk of burglary victimization is lower for students even though they have valuable property worth stealing (Robinson, 1999). The assertion that communities outside the urban core which display strong levels of territorial concern and limited access will enjoy lower crime rates may make sense (e.g., see Reppetto, 1974, pp. 86-87). However, achieving such conditions might not be necessary to reduce residential burglary victimization.

What is likely to be more effective is a community organized around irregular activities. That is, the lifestyles of individual residents should be varied. Measures which increase the volume of routine activities and decrease their regularity or predictability should be implemented. For instance, city planners and other local government agencies could alter street and pedestrian traffic so as to increase potential witnesses and, hence, the potential for surveillability.

\section{ORGANIZATION-LEVEL STRATEGIES}

Organizations can play a vital role in reducing or preventing household burglary risks. For example, police agencies can utilize crime analysis information to direct patrols to areas where residential burglaries are occurring. If these areas exhibit lower levels of routine activities or predictable lifestyle patterns, then residents can be educated about risk factors and advised how to alter lifestyle patterns or at least create the illusion of occupancy. Schools and businesses can offer the advantage of flexible schedules for parents and employees in order to accommodate more varied, less regular, and less predictable schedules of their students and 
employees. Finally, advertisements containing crime prevention techniques can be made available through the U.S. Postal Service, local news organizations, police departments, and community agencies, just to name a few. At a minimum, postal workers and newspaper delivery personnel can assist residents in decreasing the likelihood that mail and newspapers will accumulate at residences when residents are away from home. Businesses also can play a role in this effort by discontinuing current practices of leaving flyers and advertisements on doors. Such flyers and advertisements not only serve to call the attention of would-be offenders that no one is around to remove them, but also that no one is home to guard the property inside.

\section{SOCIETAL-LEVEL STRATEGIES}

Societal level changes can be encouraged to facilitate policies aimed at other levels of analysis. For example, laws permitting and encouraging tax breaks can be granted to businesses which allow their employees to work more flexible schedules. Schools can vary their schedules of children under their control to accommodate the schedules of parents. Society-wide education campaigns can be launched to make people aware of the crime prevention implications of studies such as these.

\section{ALTERATIONS TO THE PHYSICAL ENVIRONMENT}

In addition to the previous recommendations, eliminating environmental conditions conducive to burglary will alter the risk of victimization. The common recommendation of trimming shrubbery around entry points, like windows and doors, will increase surveillability from passers by and neighbors. Increased surveillability is only effective to the degree that potential witnesses feel responsible for the property at risk (Felson, 1994). Witnesses are more likely to intervene when they have a personal stake in the outcome of the victimization. Therefore, any design changes which produce increased surveillability must be accompanied by efforts to strengthen bonds between neighborhood and community members so that potential witnesses will act when they see something suspicious or out of place.

Neighbors should get to know one another and participate in publicized neighborhood watch programs. Although a recent National Institute of Justice study (Sherman, Gottfredson, MacKenzie, Eck, Reuter, \& Bushway, 1998) concluded neighborhood watches are not effective deterrents to crime, the theory behind the neighborhood watch strategy is still sound. These programs typically fail because most citizens do not get involved and there is no visible evidence of active citizen participation. Thus, neighborhood watch programs where neighbors actually participate and watch out for one another's residences are essential if surveillance is to take place. Although professional security agencies and police departments can assist in neighborhood watch efforts, the most effective crime prevention requires the assistance of citizens (Felson, 1994). 


\section{CONCLUSION}

This paper advanced several crime prevention policy implications using a systems approach from a series of environmental studies of residential burglaries. It was argued that changes made to the environments of individuals, groups, communities, organizations, and society can achieve lower risks of residential burglary. Additional changes to the physical environment also will help reduce victimization odds.

Some observers might claim that burglary victims are not to blame for their victimization. The burglar, along with the conditions which produce his or her motivation, are at fault. However, potential victims can reduce their risks of residential burglary victimization by adopting crime prevention strategies. Citizens who seek to alter their physical and social environments should focus on increasing surveillability, reducing accessibility, changing their lifestyles, and getting involved in community crime prevention activities.

\section{REFERENCES}

Bennett, T., \& Wright, R. (1984). Burglars on burglary: Prevention and the offender. Brookfield, VT: Gower Publishing.

Brown, B., \& Altman, I. (1981). Territoriality and residential crime: A conceptual framework. In P. Brantingham \& P. Brantingham (Eds.), Environmental criminology (pp. 55-76). Beverly Hills, CA: Sage.

Cohen, L., \& Cantor, D. (1981). Residential burglary in the United States: Lifestyle and demographic factors associated with the probability of victimization. Journal of Research in Crime and Delinquency, 18, 113-127.

Cohen, L., \& Felson, M. (1979). Social change and crime rate trends: A routine activity approach. American Sociological Review, 44, 588-608.

Cromwell, P., Olson, J., \& Avary, D. (1991). Breaking and entering: An ethnographic analysis of burglary. Newbury Park, CA: Sage.

Felson, M. (1987). Routine activities and crime prevention in the developing metropolis. Criminology, 25, 911-931.

Felson, M. (1994). Crime and everyday life: Insights and implications for society. Thousand Oaks, CA: Pine Forge Press.

Garofalo, J. (1987). Reassessing the lifestyle model of criminal victimization. In M. Gottfredson \& T. Hirschi (Eds.), Positive criminology (pp. 7-26). Newbury Park, CA: Sage.

Goldstein, A. (1994). The ecology of aggression. New York: Plenum Press.

Jeffery, C. R. (1990). Criminology: An interdisciplinary perspective. Englewood Cliffs, N J: Prentice-Hall. 
Maguire, M., \& Bennett, T. (1982). Burglary in a dwelling. London: Heinemann.

Miller, J. (1978). Living systems. New York: McGraw-Hill.

Rengert, G., \& Wasilchick, J. (1985). Suburban burglary: A time and place for everything.

Springfield, IL: Charles C. Thomas.

Reppetto, T. (1974). Residential crime. Cambridge, MA: Ballinger.

Robinson, M. (1997). Environmental characteristics associated with residential burglaries of student apartment complexes. Environment and Behavior, 29, 657-675.

Robinson, M. (1998a). Accessible targets but not advisable ones: The role of accessibility in student apartment burglary. Journal of Security Administration, 21, 28-44.

Robinson, M. (1998b). Cool spots of burglary. A paper presented at the annual meeting of the Southern Criminal Justice Association. October, Biloxi, MS.

Robinson, M. (1999). Lifestyles, routine activities, and residential burglary victimization. Journal of Crime and Justice, 22, 27-56.

Roundtree, P., \& Land, K. (1996). Burglary victimization, perceptions of crime risk, and routine activities: A multilevel analysis across Seattle neighborhoods and census tracts. Journal of Research in Crime and Delinquency, 33, 147-180.

Sherman, L., Gottfredson, D., MacKenzie, D., Eck,, J., Reuter, P., \& Bushway, S. (1998).

Research in brief." Preventing crime: What works, what doesn't, what's promising. Washington, D.C.: U. S. Department of Justice.

Whitehead, A. (1925). Science and the modern world. New York: MacMillan.

Winchester, S., \& Jackson, H. (1982). Residential burglary: The limits of prevention. Home Office Research Study No. 74. London: Her Majesty's Stationary Office.

Wright, R., \& Decker, S. (1994). Burglars on the job: Streetlife and residential break-ins. Boston: Northeastern University Press.

Wright, R., \& R. Logie, R. (1988). How young house burglars choose targets. The Howard Journal, 27, 92-104. 